\title{
Social Media Addiction and Empathy: Moderating Impact of Personality Traits among High School Students
}

Mohammad Dalvi-Esfahania, Ali Niknafsb, Zohre Alaedinia, Hajar Barati Ahmadabadic,*, Daria J. Kussd, T. Ramayahe,f,g,h

aAl-Mahdi Mehr Isfahan Institute of Higher Education, Isfahan, Iran bDepartment of Information Technology Management, Faculty of Management and Economics, Tarbiat Modares University, Tehran, Iran cPsychology Department, Faculty of Educational Science and Psychology, University of Isfahan, Isfahan, Iran dInternational Gaming Research Unit and Cyberpsychology Research Group, Department of Psychology, Nottingham Trent University, 50 Shakespeare Street, Nottingham NG1 4FQ, United Kingdom eSchool of Management, Universiti Sains Malaysia, Minden, 11800 Penang, Malaysia fDepartment of Management, Sunway University Business School (SUBS), Malaysia gFaculty of Economics and Business, Universiti Malaysia Sarawak, Malaysia hFaculty of Accounting and Management, Universiti Tunku Abdul Rahman (UTAR), Malaysia

Telematics and Informatics (2020). In press. https://doi.org/10.1016/j.tele.2020.101516

\begin{abstract}
Potential addiction to social media is one of the problems that some people, especially adolescents, are facing. For this reason, many studies have been conducted in this field in recent years. There is no research investigating how empathy is associated with excessive and problematic online social media use, whilst some studies have associated social media use with empathy as the main component of social development. Hence, the purpose of this study is to examine the influences of Empathic Concern (EC) and Perspective Taking (PT) on social media addiction (SMA). Moreover, prior studies revealed that Internet addiction behavior of individuals varies according to differences in personality traits.

Accordingly, impacts of EC and PT on SMA were assessed by considering differences in personality traits, which were included in the research model as moderators. To assess the research model, data collected through the distributed printed questionnaire among 592 high-school $15-18$ years old students (42.1\% male) were analyzed utilizing the partial least squares structural equation modeling (PLS-SEM) approach. The results revealed that both EC and PT significantly and negatively predict SMA. Furthermore, the moderating analysis showed that Extraversion negatively moderated the relationships between EC and SMA and PT and SMA. Further analysis revealed that while there were no differences across genders, behaviors associated with SMA were more common among students of high-income schools in contrast to low-income schools. Implications of the study are discussed.
\end{abstract}

Keywords: Internet addiction; Social media addiction; Empathy; Personality traits; High school students

\section{Introduction}

Although using social networks as one of the activities in late childhood and early adolescence has significant benefits such as emotional support, self-expression, and community building, its negative effects are also noticeable (Abbasi, 2019; Dalvi-Esfahani et al., 2019; Griffiths et al., 2018; Kuss and 
Griffiths, 2017). Excessive and problematic use of social media in adolescence is associated with excessive and problematic use of smartphones and with the parallel usage of multiple devices (Lachmann et al., 2018; Salehan and Negahban, 2013). Overuse of smartphones has been found to be associated with various negative consequences, such as problems in social interactions, being socially isolated, as well as well-being problems (including anxiety, depression, and stress) (Griffiths et al., 2018; Griffiths and Kuss, 2017; Kuss and Griffiths, 2017).

Social networks, as part of social media (Kumar and Banik, 2019), in addition to meeting cultural and social needs, enable individuals to perform social activities through computers or smartphones, track their activity in these virtual communities, and interact with other people (Tunc-Aksan and Akbay, 2019). Social media usage has increased exponentially globally (Kizgin et al., 2018), and the omnipresence of social media, including Facebook, Twitter, and Instagram has led some users to experience symptoms of addiction (Griffiths et al., 2018; Kuss and Griffiths, 2017). Research shows that young generations (especially adolescents) may be more at risk for addictive symptoms as a result of using social media (Balconi et al., 2017; Dhir et al., 2017; Sirola et al., 2019; Throuvala et al., 2019). During adolescence, children increasingly master the ability to control their behavior. These advances in self-regulation abilities in adolescence, however, are accompanied by pronounced changes in motivational processes (Gladwin et al., 2011). This can lead to changes in their behavior that increases the likelihood of addiction. For example, adolescents are more inclined to gain new experiences and risk-taking, and this can make this period a critical stage (Jordan and Andersen, 2017).

Personality traits, like extraversion and neuroticism, together with psychological states, like fear of missing out (FOMO) and no mobile phone phobia (nomophobia), are factors related to problematic use of social networks (Griffiths et al., 2018; Griffiths and Kuss, 2017). Addiction to social networking can be classed a behavioral disorder (Hou et al., 2019) that is explained as the inability to control use of social networking (Kuss and Griffiths, 2017). A recent study has examined the relationship between empathy and Internet addiction (Lachmann et al., 2018). However, studies of this kind are currently few and far between. Some studies showed there were shortcomings in social skills associated with social interactions and Internet addiction (Engelberg and Sjöberg, 2004; Guo et al., 2018; Wichstrom et al., 2019). A social skill that could affect someone's life adjustment, academic and occupational performance, is defined as one's ability to interact with others (Argyle, 1983). One of the most vital human capabilities in social interactions is empathy, which plays a crucial role in interpersonal relations (Busby and Gardner, 2008; de Wied et al., 2007). As an example, it is associated with marital satisfaction (Busby and Gardner, 2008), problem-solving in friendships (de Wied et al., 2007), and aggression inhibition (Kaukiainen et al., 1999). On the one side, there is a negative relationship between social interaction (Engelberg and Siöberg, 2004) and Internet use, and people who experience Internet addiction symptoms may sacrifice time spent with people outside of the Internet for the purpose of using the Internet (Young, 1998). On the other hand, for successful social interactions, the skill to empathize with others is essential (Busby and Gardner, 2008; Hétu et al., 2012). So, according to Melchers et al. (2015), one of the factors contributing to decreased time spent on offline interactions among Internet users may be decreased empathy. According to event-related potential research, individuals who experience Internet addiction symptoms have a deficiency in empathy (Jiao et al., 2017). Moreover, Internet use is associated with low social abilities (Engelberg and Sjöberg, 2004). Online activities compete with face-to-face social interaction rather than complementing it (Nie et al., 2008). Consequently, it is predictable that there is a significant negative relationship between empathy and 
addiction to social networks. Extending knowledge of the potential link between empathy and social media addiction (SMA) is the goal of this research. There is no research investigating the relationship between empathy and SMA, to the best of the authors' knowledge.

Empathy refers to someone's reaction to another's perceived experiences (Davis, 1983). It is defined as the skill to comprehend and share others' emotions and feelings (Decety and Lamm, 2006). Therefore, empathy consists of affective or cognitive responses to others (Davis, 1994). Other-oriented emotional responses and empathic behavior, worry for others, and warmth are considered the definition of affective empathy (Baron-Cohen and Wheelwright, 2004). Cognitive empathy is defined as the consideration of others' opinions and lets people forecast others' behaviors, and as a result, contributes to better interpersonal relationships (Davis, 1983). The cognitive aspect of empathy (also labeled perspective-taking) includes the cognitive ability to understand others' mental states (Baron-Cohen and Wheelwright, 2004). Although the distinction between these dimensions of empathy is widely acknowledged in the literature (Davis, 1983; Eisenberg et al., 2006), little is known about its impact on behavior. In this study, as in previous studies (Christov-Moore et al., 2014; Davis, 1983), empathy has been considered as a multidimensional construct.

Moreover, users' levels of SMA differs according to their personality traits, as indicated in some studies (e.g., Błachnio et al., 2017; Chung et al., 2019; Kircaburun et al., 2018; Kircaburun and Griffiths, 2018). Basically, whereas neuroticism and openness were positively associated, extraversion, agreeableness and conscientiousness traits were negatively correlated with SMA behavior, according to the results of prior studies (Błachnio et al., 2017; Griffiths et al., 2014; Kircaburun and Griffiths, 2018; Kuss et al., 2014; Zhou et al., 2017). Accordingly, in prior studies, the relationship between empathy and personality traits has been assessed (Melchers et al., 2016; Nettle, 2007; Wakabayashi and Kawashima, 2015). According to Barrio et al. (2004), the relationship between empathy and personality traits among a sample of Spanish adolescents was evaluated and it was noticed that agreeableness, openness, and conscientiousness traits were partly correlated. However, in the context of Internet addiction literature there is no study (to the best of the authors' knowledge) that investigates the moderating role of personality traits on the relationship between empathy and SMA behavior. Hence, the main objectives of the current study are as follows: (1) to investigate the influence of empathy on users' SMA behavior, and (2) to explore the moderating role of users' personality traits on the relationships between empathy and SMA.

\section{Literature review}

\section{Empathy and social media addiction}

Empathy helps recognize human psychological states (Fracero, 2006). As an essential social skill, it is explained as the ability to understand and share one's emotional state, and as a complex bio-

psychosocial construct that includes at least two components, namely affective and cognitive empathy (Davis, 1980); the first is more evolutionary-ancient and the second is human-specific (Baron-Cohen and Wheelwright, 2004; de Waal and Preston, 2017; Decety and Jackson, 2004). Recognizing what someone else is feeling, or what another person's opinion is (i.e., perspective-taking (PT)), is referred to as the cognitive component.

Understanding another person's emotions, motives, and thoughts is a skill (Baron-Cohen and Wheelwright, 2004). Feeling what someone else feels, sharing his or her emotional state (Shamay- 
Tsoory, 2011), and experiencing affective responses (like personal distress or empathic concern [EC]) are the affective component (Davis, 1996). EC is associated with the desire to help and promote behaving constructively and is other-oriented. In addition, it is described by feelings of tenderness, compassion, and softheartedness (Batson et al., 1991). Personal distress is related to the desire to relief another's unhappy state and is self-focused (Davis, 1996; Feshbach, 1997; Miller and Eisenberg, 1988).

Empathy is engraved in the human brain and developed through social interactions (Decety and Jackson, 2004). It leads to functioning appropriately within a social context (Brothers, 1989; Decety and Jackson, 2004; Singer et al., 2004). Empathy, especially in adolescence, is developed through social connectedness. Adolescents' empathy is influenced by their peers and the broader social context (Wölfer et al., 2012). Empathy improves good communication and leads to effective conflict management in relationships (Constantino, 2002; Davis, 1996; Hatfield et al., 1994). Research demonstrates that empathy relates positively to prosocial behavior (Eisenberg and Miller, 1987; Hodges et al., 2010), effective social interactions, agreeableness (Melchers et al., 2015), and negatively to aggressive and antisocial behavior (Kaukiainen et al., 1999; Loudin et al., 2003; Mehrabian and Epstein, 1972; Miller and Eisenberg, 1988). It plays a critical role in moral reasoning and inhibits aggression (Decety and Lamm, 2006). Also, research has indicated that some mental disorders are related to low empathy (Ponnampalam, 2018), for example, depression (Banzhaf et al., 2018; Gambin and Sharp, 2018), anxiety (Jütten et al., 2019), and addiction (Ferrari et al., 2014).

According to some studies, individuals who suffer from problematic Internet use (PIU) have less empathy (e.g., Jiao et al., 2017; Lachmann et al., 2018; Melchers et al., 2015). Empathy is associated with increased competence in social relationships and has a negative and inverse relationship with PIU (Caplan, 2002; Engelberg and Sjöberg, 2004). There is an inverse relationship between empathy and general Internet addiction (Hui et al., 2019), according to experimental evidence, and empathy scores in individuals scoring high on Internet addiction are considerably lower than in individuals who score low on measures of Internet addiction. There was no significant relationship between Internet overuse and empathy (Jeon et al., 2018). Since the principal goal of Internet use is to support real-life social relations, according to the authors of the study, Internet overuse is not necessarily associated with impaired empathy. Therefore, according to Nie et al. (2008), being online "competes with, rather than complements, face to face social time" (p. 215).

Accordingly, there have been conflicting results regarding the relationship between empathy and specific Internet addictions. There was no significant relationship between Internet Gaming Disorder (IGD) and empathy (Collins and Freeman, 2013; Liau et al., 2015). According to Hui et al. (2019), one of the dimensions of empathy, personal distress, had a direct and significant relationship with IGD. Liu and Wei (2018) and Wei and Liu (2020) showed that raised publicity of social media messages revealing personal suffering decreased the message receivers' empathy. Therefore, a public message, compared to a private message, can contribute to lower empathy in the receiver. Also, Linz et al. (1988) and Krahé and Möller (2010) found that the more individuals watch violent films, the less empathy they feel, which indicates observers' mirror neurons have become desensitized. Mirror neurons activate when individuals witness an action or emotion in another person (Barry, 2009; Rifkin, 2009). When using media, mirror neurons do not distinguish between what is real and what is observed. This misattribution occurs in video games, too (Barry, 2009). Therefore, if observers' brains continuously witness other people's actions and emotions on the media, their mirror neurons may become desensitized. So, it is expected that heavy media users have less empathy than individuals whose mirror neurons have not 


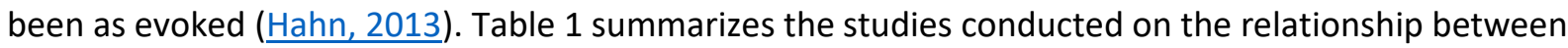
Internet addiction (general and specific) and empathy.

As shown in Table 1, the relationship between empathy and Internet addiction (general and specific) is inversely correlated if found significant. That is, low levels of empathy are associated with higher degrees of general/specific addiction to the Internet. Taken together, the following hypotheses are developed:

Hypotheses 1 and 2: Empathic concern (EC)[H1] and Perspective-taking (PT) [H2] negatively correlate with SMA.

In the literature, no studies have examined the relationship between empathy and addiction to social networks, which is a contribution to the body of knowledge to the field of Internet addiction.

\section{Personality traits and social media addiction}

Personality traits play an important role in addictive use of online applications (Rubin, 1993; $\underline{\text { Ryan et al., }}$ 2014). Individual traits forecast online communication applications use disorders (Wegmann and Brand, 2016). According to studies, increased use of Twitter and Facebook is associated with introversion, low conscientiousness, disagreeableness, and neuroticism (Kircaburun, 2016). Users of Social Media Sites (SMS) who are neurotic and who self-disclose more information (Kuss and Griffiths, 2011) are more sensitive to others' reactions to their selfies (Choi et al., 2017), and spend more time on social media (Moore and McElroy, 2012). Neuroticism is associated with the extent of social media use (Kircaburun et al., 2018). To meet new individuals, extraverted persons use social media (Horzum, 2016). Individuals who have more online friends (Amichai-Hamburger and Vinitzky, 2010), and have higher self-disclosure (Penner, 2002), post more selfies, status updates, and photos (Kim and Chock, 2017; Sorokowska et al., 2016), have more online friends (Amichai-Hamburger and Vinitzky, 2010), and have higher selfdisclosure (Misoch, 2015). Wang et al. (2015a) showed that extraversion is related to addictive use of social media. To expand their offline relationships, extraverted individuals use social media. Kuss and Griffiths (2011) explained that extraverted individuals use social media to extend their offline relationships. Yet, to compensate for their lack of off-line social relations, introverted individuals use social media and are more likely to use social media problematically (Kim and Chock, 2017; Moore and

McElroy, 2012). Agreeableness is related to addictive Instagram use (Kircaburun and Griffiths, 2018).

Less agreeable people become addicted to Instagram just for passing time and fun, and compensate for their loneliness by creating friendships online (Kircaburun et al., 2018). To maintain friendships, conscientious individuals use social media. So, to present a better picture of themselves, they use social media which can lead to problematic and excessive use. Accordingly, we posit the following hypotheses:

Hypotheses 3, 4 and 5: Openness to experience [H3], extroversion [H4], and neuroticism [H5] moderate the relationships between $\mathrm{EC} \rightarrow \mathrm{SMA}$ and $\mathrm{PT} \rightarrow \mathrm{SMA}$.

\section{Research model}

According to the aforementioned studies, the influence of the two empathy dimensions EC and PT on SMA was considered, in addition to the moderating impacts of the personality traits openness, extraversion and neuroticism as they are frequently cited in the related literature to have significant impact on Internet addiction behavior. Figure 1 illustrates the research model of the current study. 

Table 1: Prior studies on Internet addiction and empathy

\begin{tabular}{|c|c|c|c|c|c|c|}
\hline Author(s) & Context & Empathy scale & Country & $\begin{array}{l}\text { Sample } \\
\text { size }\end{array}$ & Statistical analysis & Results \\
\hline$\frac{\text { Jiao et al. }}{(2017)}$ & $\begin{array}{l}\text { Internet } \\
\text { addiction }\end{array}$ & $\begin{array}{l}\text { Event-Related } \\
\text { Potential( } \underline{\underline{\text { Jiao et al., }}} \\
\underline{\text { 2017) }}\end{array}$ & China & 32 & $\begin{array}{l}\text { two-way repeated- } \\
\text { measures ANOVA }\end{array}$ & $\begin{array}{l}\text { Lack of empathy was associated } \\
\text { with Internet addiction }\end{array}$ \\
\hline$\frac{\text { Wang et al. }}{(2014)}$ & $\begin{array}{l}\text { Internet } \\
\text { addiction }\end{array}$ & Event-Related Potential & China & 30 & Variance analysis & $\begin{array}{l}\text { Internet addiction had a direct } \\
\text { relationship with reduced } \\
\text { empathy }\end{array}$ \\
\hline$\frac{\text { Hui et al. }}{(2019)}$ & IGD & $\begin{array}{l}\text { Interpersonal Reactivity } \\
\text { Index (Penner, 2002) }\end{array}$ & China & 3,348 & $\begin{array}{l}\text { structural equation } \\
\text { modeling }\end{array}$ & $\begin{array}{l}\text { Only personal distress had a } \\
\text { direct and significant relationship } \\
\text { with IGD }\end{array}$ \\
\hline $\begin{array}{l}\text { Lachmann } \\
\frac{\text { et al. }}{(2018)}\end{array}$ & $\begin{array}{l}\text { Internet } \\
\text { addiction }\end{array}$ & $\begin{array}{l}\text { Interpersonal Reactivity } \\
\text { Index (Penner, 2002) }\end{array}$ & $\begin{array}{l}\text { China and } \\
\text { Germany }\end{array}$ & $\begin{array}{l}N=612 \\
N=304\end{array}$ & t-tests & $\begin{array}{l}\text { Significant positive relationships } \\
\text { between personal distress and } \\
\text { general Internet addiction and } \\
\text { smartphone use disorder were } \\
\text { found. }\end{array}$ \\
\hline$\frac{\text { Melchers }}{\frac{\text { et al. }}{(2015)}}$ & $\begin{array}{l}\text { Internet } \\
\text { addiction }\end{array}$ & $\begin{array}{l}\text { Interpersonal Reactivity } \\
\text { Index (Penner, 2002) }\end{array}$ & $\begin{array}{l}\text { China and } \\
\text { Germany }\end{array}$ & $\begin{array}{l}N=438 \\
N=202\end{array}$ & $\begin{array}{l}\text { ANOVA } \\
\text { Correlation analysis }\end{array}$ & $\begin{array}{l}\text { Low empathy was associated } \\
\text { with more PIU. }\end{array}$ \\
\hline$\frac{\text { Che et al. }}{\underline{(2017)}}$ & IGD & $\begin{array}{l}\text { Emotional Intelligence } \\
\text { Scale (Schutte et al., } \\
\underline{1998)}\end{array}$ & China & 931 & $\begin{array}{l}\text { bivariate correlation, } \\
\text { bootstrap methods }\end{array}$ & $\begin{array}{l}\text { There was no direct relationship } \\
\text { between empathy and IGD }\end{array}$ \\
\hline$\underline{\text { Liau et al. }}$ & IGD & $\begin{array}{l}\text { Personal Strengths } \\
\text { Inventory (Liau et al., } \\
\text { 2012) }\end{array}$ & Singapore & 3,034 & $\begin{array}{l}\text { Linear and logistic } \\
\text { regression analysis }\end{array}$ & $\begin{array}{l}\text { Although the relationship } \\
\text { between empathy and IGD was } \\
\text { negative, it was not significant. }\end{array}$ \\
\hline
\end{tabular}




\begin{tabular}{|c|c|c|c|c|c|c|}
\hline $\begin{array}{l}\text { Collins and } \\
\frac{\text { Freeman }}{(2013)}\end{array}$ & IGD & $\begin{array}{l}\text { Empathy Quotient } \\
\text { (Baron-Cohen and } \\
\text { Wheelwright, 2004) }\end{array}$ & Multinational & 416 & $\begin{array}{l}\text { Kendall's Tau } \\
\text { correlational analysis }\end{array}$ & $\begin{array}{l}\text { No significant relationship was } \\
\text { found between empathy and } \\
\text { IGD. }\end{array}$ \\
\hline$\frac{\text { Jeon et al. }}{\underline{(2018)}}$ & $\begin{array}{l}\text { Internet } \\
\text { addiction }\end{array}$ & $\begin{array}{l}\text { Empathy Quotient } \\
\text { (Baron-Cohen and } \\
\text { Wheelwright, 2004) }\end{array}$ & South Korea & 261 & $\begin{array}{l}t \text { test and } \chi 2 \text { test, } \\
\text { correlation }\end{array}$ & $\begin{array}{l}\text { No significant relationship was } \\
\text { found between empathy and } \\
\text { general Internet addiction. }\end{array}$ \\
\hline
\end{tabular}




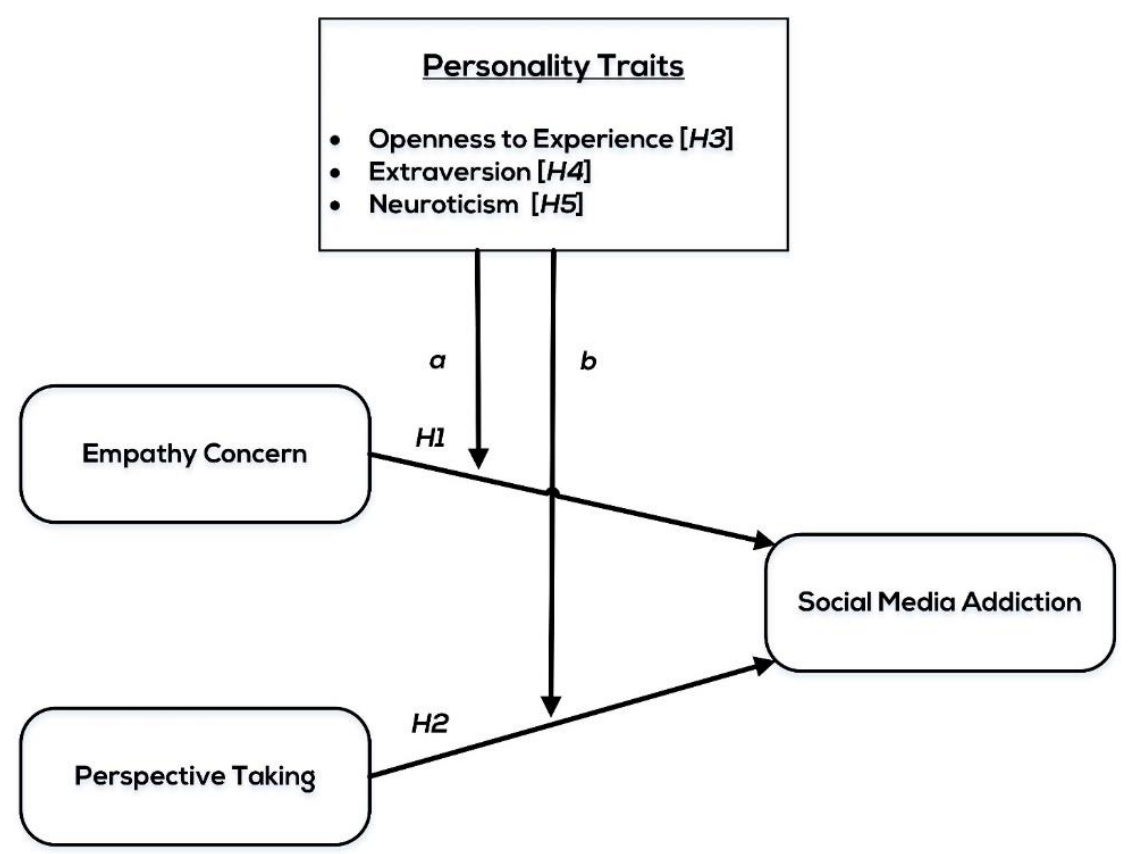

Figure 1: Research model

\section{Methodology}

Measures

Interpersonal Reactivity Index: By using the Interpersonal Reactivity Index's (Davis, 1980) items for the two dimensions of EC and PT, empathy was measured. For each dimension answered on a 5-point Likert scale ranging from 0 (does not describe me well) to 4 (describes me very well), there are seven items. Accordingly, the higher the score, the higher empathy. "I believe that there are two sides to every question and try to look at them both" (PT) and "I would describe myself as a pretty soft-hearted person" (EC) are used as sample items (Davis, 1983).

Social Media Disorder Scale: SMA was measured using the scale developed by van den Eijnden et al. (2016). The measure covers nine diagnostic criteria of addiction listed in the Diagnostic and Statistical Manual of Mental Disorders (DSM-5) (American Psychiatric Association, 2013) including Preoccupation, Tolerance, Withdrawal, Persistence, Escape, Problems, Deception, Displacement, and Conflict (three items for each). The items were preceded with the statement of "During the past year ..." and the respondents were required to answer using a 6-point ordinal scale ranging from 0 ("never") to 6 ("every day or almost every day").

NEO Five-Factor Inventory (NEO-FFI): Personality traits were measured by the NEO-Five Factor Inventory (Costa and McCrae, 1992) using a 5-point Likert scale ranging from 1 = strongly disagree to 5 = strongly agree. The inventory includes 60 items (12 items for each trait). For each trait, a mean score is calculated. The higher the mean score, the more representative the trait is of the respondent's personality.

Background information. Participants were asked their age and gender. They also responded to a checklist on what platforms they usually use (i.e., Instagram, Telegram, Facebook, WhatsApp, and 
Twitter) and for what purpose (i.e., entertainment, meeting new people, maintaining relationships, social events, content generation and sharing, and others).

Table 2: Profile of respondents

\begin{tabular}{|c|c|c|}
\hline & Frequency & Percentage \\
\hline \multicolumn{3}{|l|}{ Gender } \\
\hline Male & 249 & 42.1 \\
\hline Female & 343 & 57.9 \\
\hline \multicolumn{3}{|l|}{ School income } \\
\hline Low-income & 384 & 64.9 \\
\hline High-income & 208 & 35.1 \\
\hline \multicolumn{3}{|l|}{ Platform } \\
\hline Instagram & 586 & 99 \\
\hline Telegram & 590 & 99.7 \\
\hline Facebook & 128 & 21.6 \\
\hline WhatsApp & 592 & 100 \\
\hline Twitter & 111 & 18.7 \\
\hline \multicolumn{3}{|l|}{ Activity } \\
\hline Entertainment & 592 & 100 \\
\hline Meeting new people & 511 & 86.3 \\
\hline Maintaining relationships & 306 & 51.7 \\
\hline Social events & 275 & 46.5 \\
\hline Content generation and sharing & 588 & 99.3 \\
\hline Other & 246 & 41.6 \\
\hline
\end{tabular}

\section{Sample and data}

To assess the developed research model of the study and the related hypotheses, questionnaires were conveniently distributed in high schools in Isfahan province of Iran from March to May 2019. Due to time and budget limitations of the study, convenience sampling as one of the techniques of nonprobability sampling was applied. Target respondents were adolescent students aged between 15 to 18 (Mean $=16.46, S D=1.089)$, who were conveniently selected from seven public schools divided into 
two groups according to whether they were in a deprived district (three low-income schools) or in an affluent district (four high-income schools).

After two months, a total of 618 questionnaires were collected from seven schools, and responses from 26 participants were excluded due to incompleteness. Hence, 592 complete questionnaires were used for further analyses. Table 2 shows that the majority of respondents were female students (57.9 percent) and more than 60 percent were from low-income high schools. Instagram and Telegram were the most common social media platforms among the students for the main purposes of entertainment, content sharing and meeting new people. Using the $\mathrm{G}^{*}$ Power software and considering $f^{2}$ effect size $=$ $0.02, \alpha=0.05$, power $=0.80$ and two predictors, total sample size was calculated which shows the sample size of 592 is sufficient for PLS-SEM analysis.

\section{Data analysis}

Since the purpose of the study was to predict SMA by EC and PT and the latent variable scores were planned to be utilized in a subsequent analysis, partial least squares structural equation modeling (PLSSEM) was used (Hair and Hult, 2016). PLS is one of the variance-based SEM (VBSEM) examples and is more suitable for theory predicting than covariance-based SEM (CBSEM) examples (such as AMOS) (Henseler et al., 2009). The PLS algorithm maximizes the explained variance of all dependent variables and does not require adhering to multivariate assumptions (e.g., normality in distribution, linearity of relationships, homoscedasticity of variance and no multicollinearity issues) (Hew and Syed A. Kadir, 2017). PLS-SEM can assess both measurement and structural models simultaneously. SmartPLS 3.0 software was used to analyze the data through a two-step analysis approach (Hair et al., 2011). To assess the significance level of path coefficients a bootstrapping method (5000 resamples) was utilized.

\section{Common method bias}

To confirm the common method bias (CMB), Harman's single factor showed that $40.06 \%$ of total variance was explained. Hence, $\mathrm{CMB}$ is a non-issue.

\section{Results}

\section{Measurement model assessment}

To assess the measurement model, related constructs were examined for their indicator reliability (outer loadings $>0.7$ ), internal consistency (composite reliability $>0.7$ ), convergent validity (average variance extracted $>0.50$ ) and discriminant validity.

To assess the discriminant validity of the measurement model, heterotrait-monotrait ratio (HTMT) criteria were used. This criterion assesses what would be the true correlation between two variables if they were perfectly measured. The threshold value of 0.90 is suggested by Henseler et al. (2015) for the models containing variables that are conceptually very similar. Table 3 shows that all HTMT values are lower than the threshold value of 0.90. Besides assessing the values of HTMT ratios, it should be examined whether the values are significantly different from 1. To do so, confidence intervals of values were obtained utilizing the bootstrapping method approach. The results showed none of the confidence intervals included the value 1. HTMT threshold values together with the results obtained from bootstrapping confidence intervals supported discriminant validity of the constructs. Tables 3 and 4 summarize the validity and reliability assessment of the measurement model. The results of the 
measurement model assessment show that the collected data are valid and reliable and usable for the structural model assessment.

Table 3: Discriminant validity - HTMT ratios

\begin{tabular}{|c|c|c|c|c|c|c|}
\hline & EC & EX & NT & OP & PT & SMD \\
\hline \multicolumn{7}{|l|}{ Empathy Concern } \\
\hline Extraversion & 0.492 & & & & & \\
\hline Neuroticism & 0.668 & 0.662 & & & & \\
\hline Openness & 0.494 & 0.821 & 0.775 & & & \\
\hline Perspective Taking & 0.897 & 0.619 & 0.738 & 0.661 & & \\
\hline Social Media Addiction & 0.672 & 0.498 & 0.722 & 0.438 & 0.707 & \\
\hline
\end{tabular}

Table 4: Summary of the measurement model assessment

\begin{tabular}{llll}
\hline Construct & $\begin{array}{l}\text { Composite } \\
\text { reliability }\end{array}$ & AVE & $\begin{array}{l}\text { HTMT confidence interval does not } \\
\text { include 1 }\end{array}$ \\
\hline Social media addiction & 0.98 & 0.60 & Yes \\
Empathy concern & 0.96 & 0.77 & Yes \\
Perspective-taking & 0.94 & 0.70 & Yes \\
Openness & 0.93 & 0.54 & Yes \\
Extraversion & 0.95 & 0.59 & Yes \\
Neuroticism & 0.94 & 0.55 & Yes \\
\hline
\end{tabular}

Table 5: Structural model assessment

\begin{tabular}{lllllllll}
\hline Hypothesis & Relationship & $R^{2}$ & Path coefficient & $M$ & $S D$ & $\begin{array}{l}t- \\
\text { value }\end{array}$ & $p$-value & Result \\
& & & & & & & \\
\hline H1 & EC $\rightarrow$ SMA & 0.37 & -0.432 & -0.425 & 0.069 & 6.250 & $0.000^{*}$ & Accepted \\
H2 & PT $\rightarrow$ SMA & & -0.199 & -0.197 & 0.073 & 2.710 & $0.007^{*}$ & Accepted \\
\hline
\end{tabular}

Notes:

SMA = Social media addiction 


$$
\begin{aligned}
& \text { EC = Empathic Concern } \\
& \text { PT = Perspective Taking } \\
& M=\text { Standard mean } \\
& \text { SD }=\text { Standard deviation } \\
& * p<0.01 \text { (two-tailed test) }
\end{aligned}
$$

Table 6: Empathy as the higher-order construct

\begin{tabular}{llllllll}
\hline Relationship & $R^{2}$ & Path coefficient & $M$ & $S D$ & $t$-value & $\begin{array}{l}p \text { - } \\
\text { value }\end{array}$ & Result \\
& & & & & & & \\
\hline Empathy $\rightarrow$ SMD & 0.37 & -0.607 & -0.602 & 0.049 & 12.335 & $0.000^{*}$ & Accepted \\
\hline
\end{tabular}

\section{Structural model assessment}

Since the dependent construct (i.e., social media addiction) is considered the higher-order construct, latent variable scores were used to perform the structural model assessment and further analyses. The results of the analysis are presented in Table 5 . The results show that $37 \%$ of the variance in SMD is explained by EC and PT. The path coefficients of both relationships are negative which indicates a reverse correlation. Individuals with higher degrees of EC and PT showed lower degrees of social media addiction behavior. By considering empathy as the higher order construct, the correlation between empathy and social media addiction is showed in Table 6.

\section{Moderation analysis}

To analyze the moderating effect of personality traits, the product indicator approach was used (Hair and Hult, 2016). Results showed that openness moderated the relationship between PT and SMA, such that the relationship was positive when openness was low, but negative when openness was high (Figure 2a). For the relationship between EC and SMA (Figure 2b), openness did not change the nature of the relationship, but those with low openness tended to be more prone to SMA. Extraversion changed the nature of the relationships EC $\rightarrow$ SMA and PT $\rightarrow$ SMA (see Figures $2 c$ and $2 d$ ). For individuals with lower degrees of extraversion, the relationships were positive, but negative for the ones with higher degrees of extraversion. For the moderating impact of neuroticism, simple slope plots (see Figures $2 \mathrm{e}$ and $2 \mathrm{f}$ ) showed that neuroticism strengthened the positive relationship between PT and SMA. For the relationship between EC and SMA, the relationship was positive for those with low degrees of neuroticism, but slightly negative for those with high degrees of neuroticism.

To assess whether the interaction terms were significant, the bootstrapping method was used; results are presented in Table 7. The results showed that openness did not moderate the relationships EC $\rightarrow$ SMA and PT $\rightarrow$ SMA. However, for extraversion the interaction terms were both significant which indicates that the moderating impact of extraversion on the relationships with SMA was significant. None of the relationships were significantly moderated by neuroticism. 
Table 7: Interaction term assessment of personality traits as moderators

\begin{tabular}{llllllll}
\hline & Hypothesis & Relationship & $\begin{array}{l}\text { Interaction } \\
\text { term }\end{array}$ & $M$ & $S D$ & $t$-value & $p$-value \\
Openness & $\mathrm{H} 3 \mathrm{a}$ & $\mathrm{EC} \rightarrow \mathrm{SMA}$ & -0.084 & -0.088 & 0.077 & 1.089 & 0.227 \\
& $\mathrm{H} 3 \mathrm{~b}$ & $\mathrm{PT} \rightarrow \mathrm{SMA}$ & 0.107 & 0.118 & 0.087 & 1.224 & 0.222 \\
\multirow{5}{*}{ Extraversion } & $\mathrm{H} 4 \mathrm{a}$ & $\mathrm{EC} \rightarrow \mathrm{SMA}$ & -0.220 & -0.220 & 0.063 & 3.494 & $0.002^{*}$ \\
& $\mathrm{H} 4 \mathrm{~b}$ & $\mathrm{PT} \rightarrow \mathrm{SMA}$ & -.0386 & -0.392 & 0.075 & 5.133 & $0.000^{*}$ \\
\multirow{5}{*}{ Neuroticism } & $\mathrm{H} 5 \mathrm{a}$ & $\mathrm{EC} \rightarrow \mathrm{SMA}$ & 0.061 & 0.062 & 0.064 & 0.935 & 0.953 \\
& $\mathrm{H} 5 \mathrm{~b}$ & $\mathrm{PT} \rightarrow \mathrm{SMA}$ & -0.055 & -0.055 & 0.068 & 0.817 & 0.414 \\
\hline
\end{tabular}

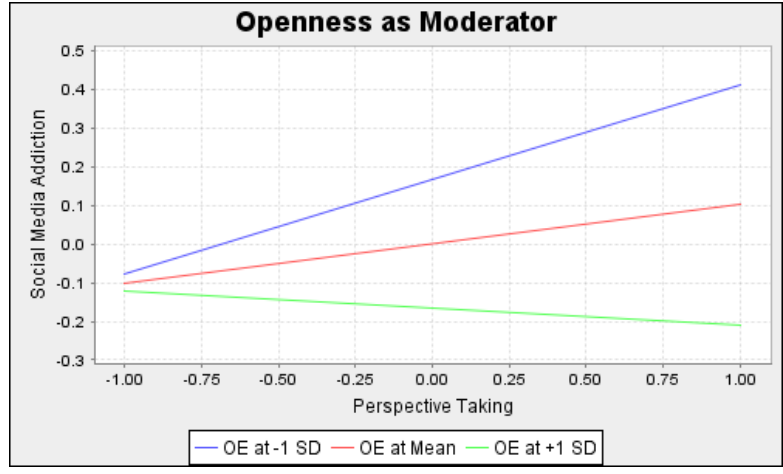

(a)

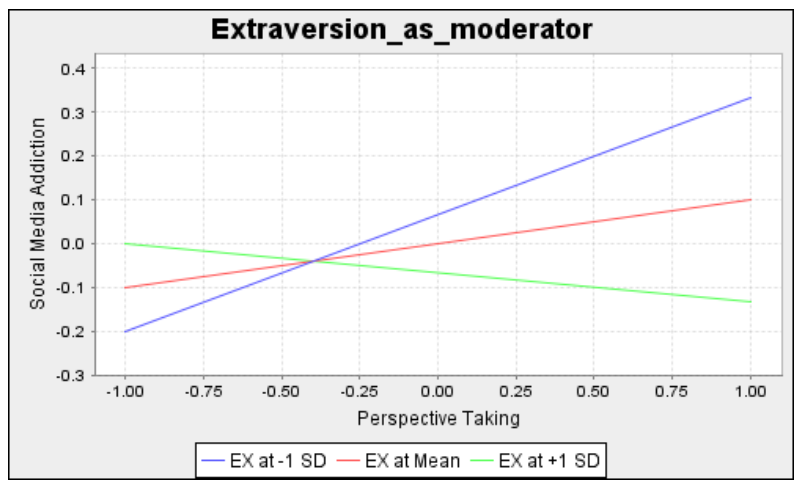

(c)

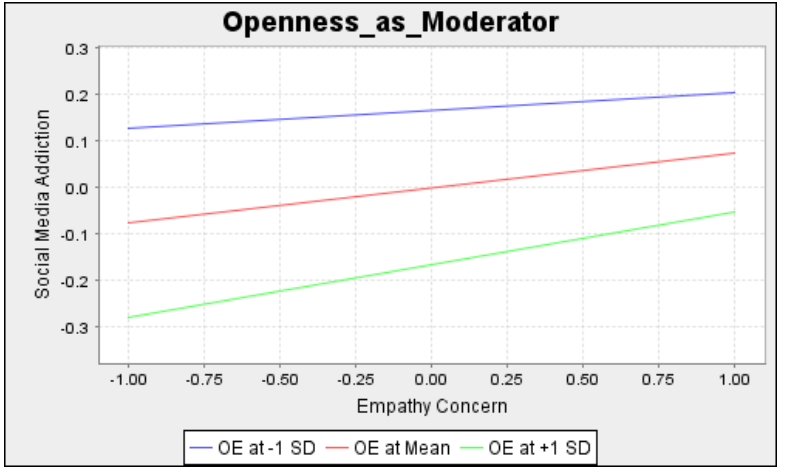

(b)

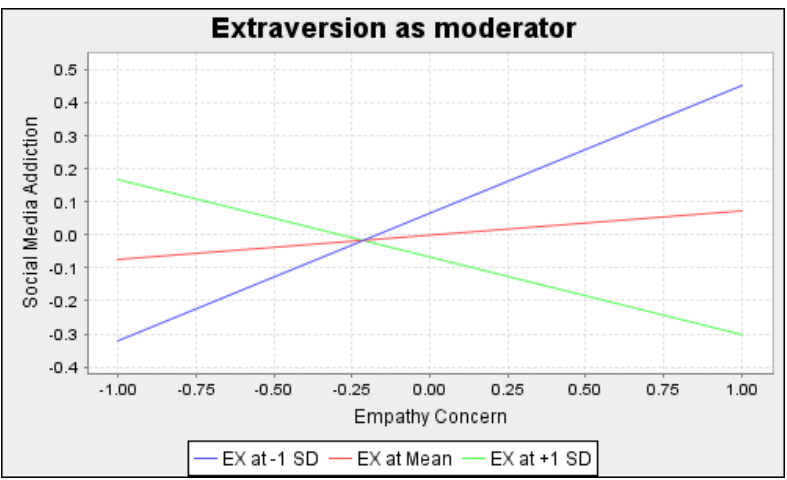

(d) 


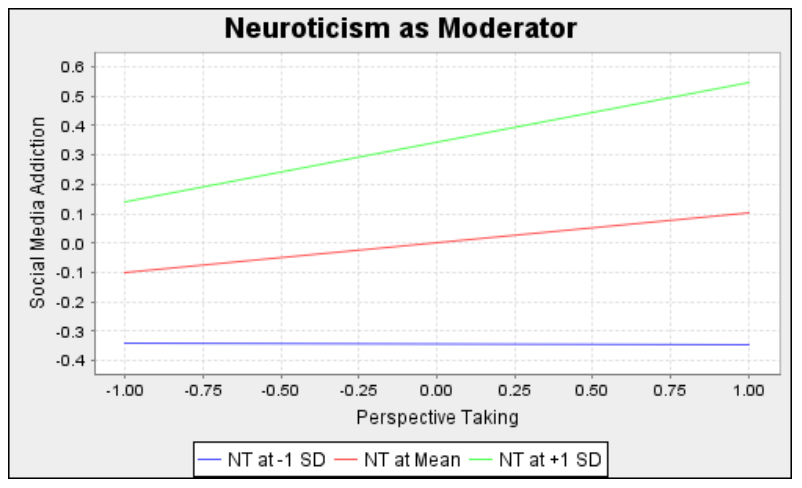

(e)

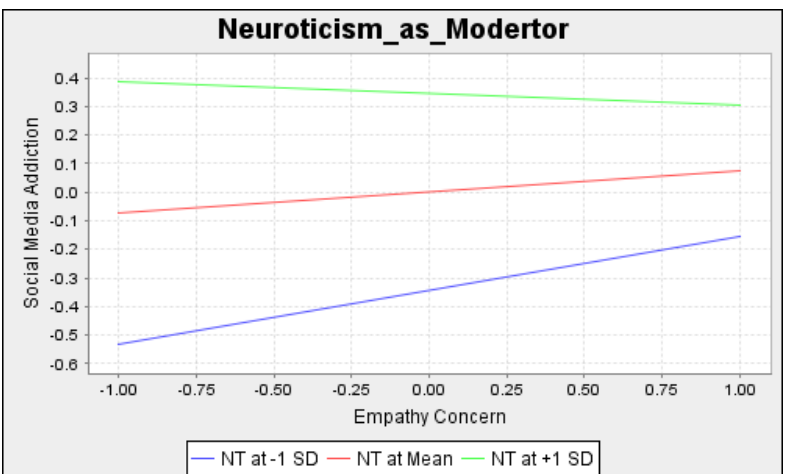

(f)

Figure 2: Personality traits as moderators

\section{Further analysis}

Further analysis was performed to investigate whether there were differences for gender (male vs. female) and school income (high-income vs. low-income). Accordingly, a series of ANOVAs were performed, and the results showed that the income groups differed significantly on SMD (i.e., on tolerance, persistence, problem, and displacement). Multiple comparisons of means revealed that the high income group displayed higher levels of SMD. More specifically, students with high socioeconomic level demonstrated the tendency to spend an increased amount of time engaged in social medias to gain the desired satisfaction (tolerance), unsuccessful attempts to control or stop online social networking activities (persistence), continued use of social medias despite the awareness of adverse consequence (problem), and diminished offline social activities due to excessive social media use (displacement). The difference in boys and girls was not significant. The interaction between gender and income was not significant. This means that high-income school students were more likely to display higher levels of SMD, regardless of their gender. The results are summarized in Table 8.

\section{Discussion}

Investigating the effect of two empathy dimensions, i.e., empathic concern and perspective taking, on social media addiction, along with the moderating effects of the personality traits openness, extraversion, and neuroticism was the goal of this research. The results indicate empathy had a negative relationship with SMA. These findings are in line with previous studies (Blakemore and Agllias, 2020; Ibrahim, 2019; Jeong and Lee, 2015; JING et al., 2017; Lachmann et al., 2018b; Melchers et al., 2015). Dailey et al. (2020) suggested that empathetic social media users may be more resilient against addiction. Empathy enhances the fundamental capacity of individuals to form relationships, supports collaborative activities, and promotes group cohesion (Morelli et al., 2015). This ability has a central role in social life and motivates social behavior. Empathy allows individuals to share in each other's feelings and leads to establishing good relationships (Jackson et al., 2015). Empathy helps people understand each other's affective and cognitive experiences, which may facilitate awareness of self and others (Riess, 2015). More precisely, empathy makes relationships desirable (Hirn et al., 2019), so individuals with high empathy may feel a lower need to engage with others online. They can satisfy the need for belonging (Maslow, 1943) and the need for affiliation (McClelland, 1965) offline. However, individuals 
with low empathy may not be able to have pleasant relationships in the real world and use social media and internet interactions to compensate for this deficiency. Individuals may compensate for low social competency and low wellbeing by increased social media use, which may explain the relationships between low empathy and SMA. In particular, it has been found that empathic concern, or the affective dimension of "empathy," empowers people with interpersonal skills such as expressing friendship and resolving conflict, which leads to better relationships (Shalchi, 2018). Empathic concern means to be kind and sympathetic towards others. Perspective-taking, or the cognitive dimension of "empathy," includes the understanding of the emotional state and point of view of the other person, which leads to promoting social cognition (Taher et al., 2016). When a person has a pleasant experience, an empathetic individual who is aware of his or her success and enjoyment can also experience pleasure vicariously. In other words, since warm empathy is a vicarious experience of another person's emotions and feelings, it provides very accurate information and can actualize potential humanitarian desires (Mcllwain, 2003). A person with high empathy may experience 
Table 8: Mean differences in SMA and Empathy based on Income, Gender, and Gender*Income

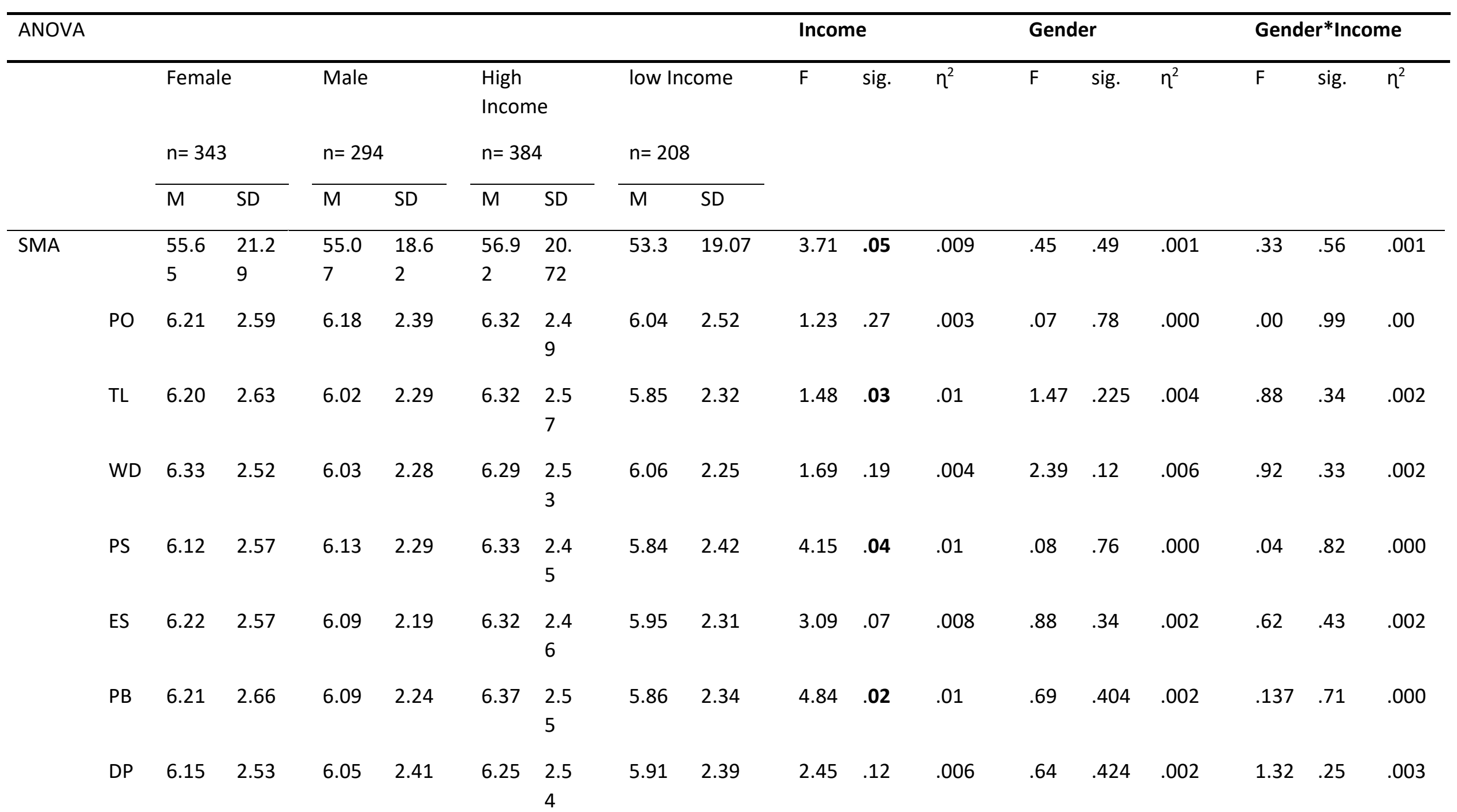




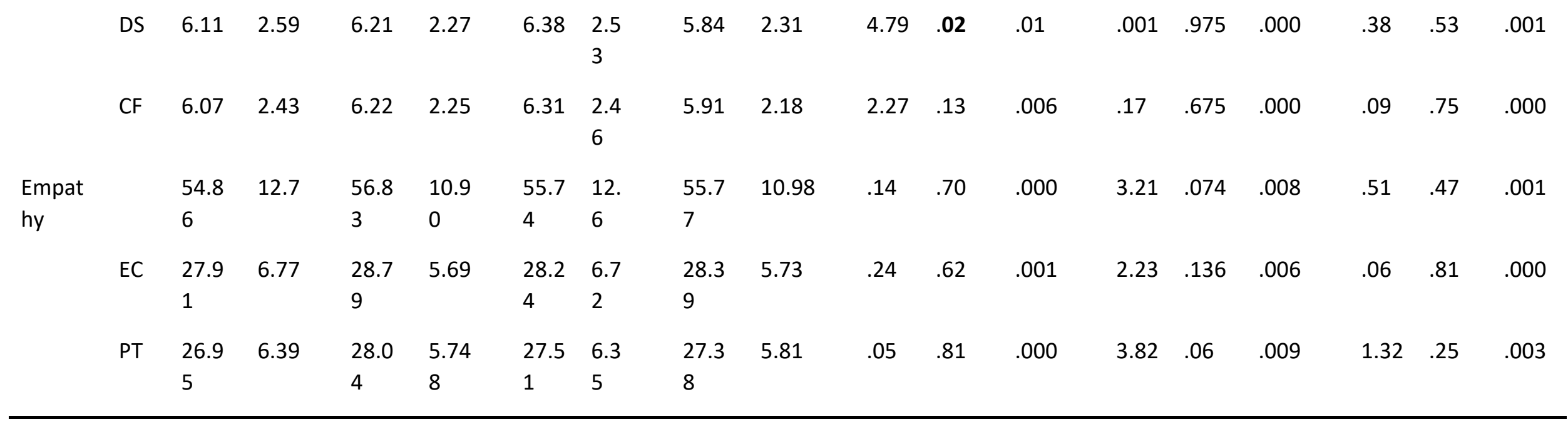

Notes:

$\mathrm{M}=$ Mean; $\mathrm{SD}=$ Standard Deviation; $\mathrm{SMD}=$ Social Media Addiction; $\mathrm{PO}=$ Preoccupation; $\mathrm{TL}=$ Tolerance WD = Withdrawal; $\mathrm{PS}=$ Persistence; $\mathrm{ES}=\mathrm{Escape} ; \mathrm{PB}$ = Problem; DP = Deception; DS = Displacement CF = Conflict; $\mathrm{EC}=$ Empathic Concern; $\mathrm{PT}=$ Perspective Taking 
more positive interactions with others offline and may therefore not need to spend increased amounts of time on social media, and therefore, their experiences of SMA may be low as a consequence.

Of the assessed personality traits, extraversion has a moderating role in the relationship between empathy and SMA. The opposite relationship of empathy and addiction is stronger in extroverted people than introverted ones. Previous research confirmed that extraversion predicts internet addiction and SMA (Biolcati et al., 2018; Blackwell et al., 2017; Caers et al., 2013; Marengo et al., 2020; Rajesh and Rangaiah, 2020; Wang et al., 2015b).

Extroverts need to have high empathy because they have larger numbers of social relationships. Still, extroverts with low empathy turn to social media to provide these relationships and therefore are more likely to develop problems as a consequence of their social media use. A possible explanation of this relationship may be related to the characteristics of extroverted individuals. Extroverts are empathetic, warm, friendly, assertive, active, sensation seekers, and have positive emotions (Rathore, 2019). The warmth and strong communication skills of extroverted individuals facilitate the process of relationship building. In communication with extroverted people, warmth and acceptance will be exchanged; as a result, emotions are expressed more openly, and empathy will be facilitated (Shalchi, 2018). These characteristics of extroverts also illustrate why extraversion is inversely related to SMA. Spending a lot of time on social media may require limiting human relationships offline, which is not compatible with the characteristics of extroverts (Bazrafshan et al., 2018).

The current study did not confirm the moderating role of neuroticism and openness to experience in the relationship between empathy and SMA. However, individuals who score highly on neuroticism are more likely to experience problematic Internet use because they want to increase their self-esteem by joining social groups and developing a sense of belonging (Chang et al., 2019). Neurotics are characterized by anxiety, fear, and insecurity in relationships, which leads to feeling helpless, having poor perspective-taking, and consequently, low empathy (Shalchi, 2018). However, neuroticism is a prominent predictor of SMA (Andreassen et al., 2013; Blackwell et al., 2017; Kandell, 1998; Marengo et al., 2020; Tang et al., 2016; Tsai et al., 2009), but it did not moderate the relationship between empathy and SMA in this study.

Openness to experience also did not moderate the relationship between empathy and SMA. In the case of openness to experience, the findings in the relevant literature are inconsistent. Some indicate that it

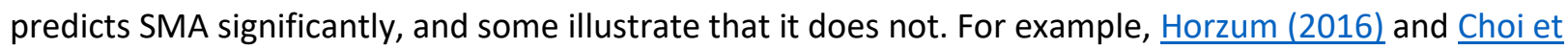
al. (2017) demonstrated that openness to experience is negatively related to social media use. On the contrary, Amichai-Hamburger and Vinitzky (2010) and Kosinski et al. (2014) found people who score high on openness to experience use social media more. Kircaburun et al. (2018) indicated that openness to experience is not related to problematic social media use. Openness to experience entails having new thoughts and beliefs, curiosity, intelligence, and acceptance of challenges. People who are open to experience explore their inner and outer world, enjoy engaging with new things and a lot of interests. These features may be related to SMA (Hawi and Samaha, 2019). On the other hand, individuals scoring high on openness to experience tend to be more liberal and free from prejudice and dogmatism (Sawyer, 2011).

The results also showed that high-income school students had higher SMA scores. This finding is consistent with previous research. For example, data of the Pew Internet and American life project showed that Internet use varied across countries with different socioeconomic environments. In 
particular, increased Internet use is positively associated with higher earnings and higher educational qualifications (Przybylski and Murayama, 2013). Research has also shown that children from more favorable socioeconomic backgrounds are more at risk for Internet addiction (Billieux et al., 2015). Przybylski and Murayama (2013) also point out that despite the increasing distribution of computers and growing use of the Internet worldwide, there is still a large gap between those who have more financial resources, education, and skills to use technology and those who do not. Alt (2015) showed that in highincome schools, there are significantly more students with, or at risk of, Internet addiction. Yujia et al. (2017) have also discussed that Internet addiction has a lower prevalence in individuals from lower socioeconomic backgrounds in that adolescents have less access to the Internet. Some adolescents may have to work or take additional responsibilities within their families, and therefore have less leisure time. Wealthier families may provide more facilities and opportunities for Internet access. Besides, according to Elhai et al. (2016), parents' and educators' attitudes to technology differ across social classes, with wealthier families increasingly considering the positive effects of digital media on child development. Finally, one of the reasons may be related to the overall ability of individuals who come from higher income households to pay for the Internet and computer games. They may also use social media as a desirable way to display their assets, such as images of luxury items and expensive cars.

\section{Conclusion}

The current study explored the influence of empathy on social media addiction among high school students by considering the personality traits of neuroticism, extraversion and openness as moderating variables. The results revealed that empathic concern together with perspective taking negatively and significantly impacted SMA among the adolescents. Furthermore, the results showed that extraversion was the only significant moderating variable in the research model. By applying a series of ANOVAs, it was revealed that while there was no difference between boys and girls, adolescents from high-income families showed higher scores of SMA than adolescents from lower income families.

\section{Limitations and future research directions}

Agreeableness and conscientiousness were not assessed in this research, which can be considered a limitation. Therefore, subsequent studies should assess them. Moreover, there are limitations regarding generalizability since this study was conducted on a special sample within a particular culture. Using a cross-sectional design for questionnaire data collection is another limitation that limits making causal inferences. Finally, a bias may have been introduced in the results by certain properties of the utilized self-report tools (i.e., use of a brief scale for assessing personality traits). The present findings highlight the critical role of empathy in protecting against SMA. This kind of research on adolescents can help identify the factors that contribute to SMA as well as provide insight into new opportunities for prevention, diagnosis, and treatment. According to the findings, empathy decreased the risk for SMA and was therefore a protective factor; therefore, empathy training may play a crucial role in preventing Internet addiction. Since adolescents are the most vulnerable age group for SMA (Dailey et al., 2020; Wolniewicz et al., 2018), risk factors should be identified and controlled for, where possible. By using longitudinal designs, future studies can help further assess the nature of underlying mechanisms that are associated with empathy, personality traits, and SMA. Moreover, it is recommended to evaluate interventions to improve empathy in adolescents.

Research implications 
IGD has been included in the DSM-5 and Gaming Disorder in the ICD-11, indicating that a particular use of the Internet may be associated with addictive symptoms (Kuss and Griffiths, 2017b). For this reason, several studies have started to explore different types of Internet addiction. Social media addiction, as one of the specific types of Internet addiction, has also been considered by researchers and various studies have investigated various aspects of it. Due to increased risk in adolescence, a large percentage of studies focus on the negative effect of excessive and problematic use of social networks on adolescent mental health (Sherlock and Wagstaff, 2018), academic performance (González et al., 2016), personality disorders (Zhou et al., 2017), comorbid symptoms such as depression (Zhao et al., 2017), and FOMO (Dhir et al., 2018), among other symptoms. Although scattered studies have examined the relationship between empathy and different types of Internet addiction, there are no studies on the relationship between empathy and social media addiction in the existing literature. Furthermore, very few studies investigated the moderating impact of personality traits on SMA behavior. Hence, the present study contributes to the existing body of knowledge of Internet addiction literature by investigating the impact of empathy on SMA and further considering personality traits as moderating variables.

\section{Practical implications}

The findings of this study, along with the theoretical contributions that it provides to the existing body of knowledge of Internet addiction, can also have practical implications. The findings of this study can be used to provide scientific solutions to cope with SMA to students, parents, teachers, counselors and psychotherapists. Empathy for the feelings and needs of others is an important skill to develop. Developing empathy in adolescents is important because it teaches them to reflect, observe, and think about their behavior. The results of this study showed that students who have more empathic concern and perspective taking than others showed fewer symptoms of SMA. Therefore, by strengthening empathy among adolescents and students, the likelihood of their experience of SMA can be reduced. One of the steps that parents and teachers can take to strengthen empathy in students and adolescents is to provide them with the support they need to develop and strengthen their self-regulatory skills. Adolescents who are better at regulating their negative emotions tend to show more empathic concern towards others. One of the best approaches to encourage empathy is to make children aware of what they have in common with others. Although affective empathy (empathic concern) and strengthening it is appropriate, parents and teachers should pay special attention to cognitive empathy (perspective taking) as well. 


\section{References}

Abbasi, I. S. (2019). Social media addiction in romantic relationships: Does user's age influence vulnerability to social media infidelity? Personality and Individual Differences, 139, 277-280.

Alt, D. (2015). College students' academic motivation, media engagement and fear of missing out. Computers in Human Behavior, 49, 111-119.

American Psychiatric Association. (2013). Diagnostic and Statistical Manual of Mental Disorders (DSM$\left.5^{\circledR}\right)$ : American Psychiatric Association.

Amichai-Hamburger, Y., and Vinitzky, G. (2010). Social network use and personality. Computers in Human Behavior, 26(6), 1289-1295.

Andreassen, C. S., Griffiths, M. D., Gjertsen, S. R., Krossbakken, E., Kvam, S., and Pallesen, S. (2013). The relationships between behavioral addictions and the five-factor model of personality. Journal of Behavioral Addictions, 2(2), 90-99.

Argyle, M. (1983). The psychology of interpersonal behavior. Harmondsworth, England: Penguin.

Balconi, M., Venturella, I., and Finocchiaro, R. (2017). Evidences from rewarding system, FRN and P300 effect in Internet-addiction in young people. Brain Sciences, 7(7), 81.

Banzhaf, C., Hoffmann, F., Kanske, P., Fan, Y., Walter, H., Spengler, S., et al. (2018). Interacting and dissociable effects of alexithymia and depression on empathy. Psychiatry Research, 270, 631-638.

Baron-Cohen, S., and Wheelwright, S. (2004). The empathy quotient: An investigation of adults with Asperger Syndrome or high functioning Autism, and normal sex differences. Journal of Autism and Developmental Disorders, 34(2), 163-175.

Barrio, V. d., Aluja, A., and García, L. F. (2004). Relationship between empathy and the Big Five personality traits in a sample of Spanish adolescents. Social Behavior and Personality: an international journal, 32(7), 677-681.

Barry, A. M. (2009). Mirror neurons: How we become what we see. Visual Communication Quarterly, 16(2), 79-89.

Batson, C. D., Batson, J. G., Slingsby, J. K., Harrell, K. L., Peekna, H. M., and Todd, R. M. (1991). Empathic joy and the empathy-altruism hypothesis. Journal of Personality and Social Psychology, 61(3), 413.

Bazrafshan, M., Ghaedian, S., Foroutani, M., and Gholami, Y. (2018). An analysis of secondary high school students' personality dimensions and the use of virtual social networks in the 4th District of Shiraz City, 2014. Journal of Rafsanjan University of Medical Sciences, 16(10), 913-924.

Billieux, J., Maurage, P., Lopez-Fernandez, O., Kuss, D. J., and Griffiths, M. D. (2015). Can disordered mobile phone use be considered a behavioral addiction? An update on current evidence and a comprehensive model for future research. Current Addiction Reports, 2(2), 156-162.

Biolcati, R., Mancini, G., Pupi, V., and Mugheddu, V. (2018). Facebook addiction: Onset predictors. Journal of Clinical Medicine, 7(6), 118. 
Błachnio, A., Przepiorka, A., Senol-Durak, E., Durak, M., and Sherstyuk, L. (2017). The role of personality traits in Facebook and Internet addictions: A study on Polish, Turkish, and Ukrainian samples. Computers in Human Behavior, 68, 269-275.

Blackwell, D., Leaman, C., Tramposch, R., Osborne, C., and Liss, M. (2017). Extraversion, neuroticism, attachment style and fear of missing out as predictors of social media use and addiction. Personality and Individual Differences, 116, 69-72.

Blakemore, T., and Agllias, K. (2020). Social media, empathy and interpersonal skills: Social work students' reflections in the digital era. Social Work Education, 39(2), 200-213.

Brothers, L. (1989). A biological perspective on empathy. American Journal of Psychiatry, 146(1), 10-19.

Busby, D. M., and Gardner, B. C. (2008). How do I analyze thee? Let me count the ways: Considering empathy in couple relationships using self and partner ratings. Family Process, 47(2), 229-242.

Caers, R., De Feyter, T., De Couck, M., Stough, T., Vigna, C., and Du Bois, C. (2013). Facebook: A literature review. New Media \& Society, 15(6), 982-1002.

Caplan, S. E. (2002). Problematic Internet use and psychosocial well-being: Development of a theorybased cognitive-behavioral measurement instrument. Computers in human behavior, 18(5), 553-575.

Chang, Y.-H., Lee, Y.-T., and Hsieh, S. (2019). Internet interpersonal connection mediates the association between personality and internet addiction. International Journal of Environmental Research and Public Health, 16(19), 3537.

Che, D., Hu, J., Zhen, S., Yu, C., Li, B., Chang, X., et al. (2017). Dimensions of emotional intelligence and online gaming addiction in adolescence: The indirect effects of two facets of perceived stress. Frontiers in Psychology, 8, 1206.

Choi, T. R., Sung, Y., Lee, J.-A., and Choi, S. M. (2017). Get behind my selfies: The Big Five traits and social networking behaviors through selfies. Personality and Individual Differences, 109, 98-101.

Christov-Moore, L., Simpson, E. A., Coudé, G., Grigaityte, K., lacoboni, M., and Ferrari, P. F. (2014). Empathy: Gender effects in brain and behavior. Neuroscience \& Biobehavioral Reviews, 46, 604-627.

Chung, K. L., Morshidi, I., Yoong, L. C., and Thian, K. N. (2019). The role of the dark tetrad and impulsivity in social media addiction: Findings from Malaysia. Personality and Individual Differences, 143, 62-67.

Collins, E., and Freeman, J. (2013). Do problematic and non-problematic video game players differ in extraversion, trait empathy, social capital and prosocial tendencies? Computers in Human Behavior, 29(5), 1933-1940.

Constantino, J. (2002). Deconstructing empathy. Behavioral and Brain Sciences, 25, 1-72.

Costa, P. T., and McCrae, R. R. (1992). Revised NEO personality inventory (NEO-PI-R) and NEO five-factor inventory (NEO-FFI): Professional manual. Lutz, FL: Psychological Assessment Resources (PAR).

Dailey, S. L., Howard, K., Roming, S. M., Ceballos, N., and Grimes, T. (2020). A biopsychosocial approach to understanding social media addiction. Human Behavior and Emerging Technologies, 1-10. 
Dalvi-Esfahani, M., Niknafs, A., Kuss, D. J., Nilashi, M., and Afrough, S. (2019). Social media addiction: Applying the DEMATEL approach. Telematics and Informatics, 43, 101250.

Davis, M. H. (1980). A multidimensional approach to individual differences in empathy (Vol. 10). Corte Madera, CA.

Davis, M. H. (1983). Measuring individual differences in empathy: Evidence for a multidimensional approach. Journal of Personality and Social Psychology, 44(1), 113-126.

Davis, M. H. (1994). Empathy: A Social Psychological Approach. Madison, WI: Brown and Benchmark Publishers.

Davis, M. H. (1996). Empathy: a social psychological approach (Social Psychology). Florida: Westview Press.

de Waal, F. B., and Preston, S. D. (2017). Mammalian empathy: Behavioural manifestations and neural basis. Nature Reviews Neuroscience, 18(8), 498.

de Wied, M., Branje, S. J. T., and Meeus, W. H. J. (2007). Empathy and conflict resolution in friendship relations among adolescents. Aggressive Behavior, 33(1), 48-55.

Decety, J., and Jackson, P. L. (2004). The functional architecture of human empathy. Behavioral and Cognitive Neuroscience Reviews, 3(2), 71-100.

Decety, J., and Lamm, C. (2006). Human empathy through the lens of social neuroscience. The Scientific World Journal, 6.

Dhir, A., Kaur, P., Lonka, K., and Tsai, C.-C. (2017). Do psychosocial attributes of well-being drive intensive Facebook use? Computers in Human Behavior, 68, 520-527.

Dhir, A., Yossatorn, Y., Kaur, P., and Chen, S. (2018). Online social media fatigue and psychological wellbeing-A study of compulsive use, fear of missing out, fatigue, anxiety and depression. International Journal of Information Management, 40, 141-152.

Eisenberg, N., and Miller, P. A. (1987). The relation of empathy to prosocial and related behaviors. Psychological Bulletin, 101(1), 91.

Eisenberg, N., Spinrad, T. L., and Sadovsky, A. (2006). Empathy-related responding in children. Handbook of Moral Development, 517, 549.

Elhai, J. D., Levine, J. C., Dvorak, R. D., and Hall, B. J. (2016). Fear of missing out, need for touch, anxiety and depression are related to problematic smartphone use. Computers in Human Behavior, 63, 509-516.

Engelberg, E., and Sjöberg, L. (2004). Internet use, social skills, and adjustment. CyberPsychology \& Behavior, 7(1), 41-47.

Ferrari, V., Smeraldi, E., Bottero, G., and Politi, E. (2014). Addiction and empathy: A preliminary analysis. Neurological Sciences, 35(6), 855-859.

Feshbach, N. D. (1997). Empathy: The formative years-- Implications for clinical practice. In A. C. Bohart \& L. S. Greenberg (Eds.), Empathy reconsidered: New directions in psychotherapy (p. 33-59). American 
Psychological Association. https://doi.org/10.1037/10226-001 Fracero, K. E. (2006). Building relationships powered by empathy. Contract Management, 46(8), 4-6.

Gambin, M., and Sharp, C. (2018). The relations between empathy, guilt, shame and depression in inpatient adolescents. Journal of Affective Disorders, 241, 381-387.

Gladwin, T. E., Figner, B., Crone, E. A., and Wiers, R. W. (2011). Addiction, adolescence, and the integration of control and motivation. Developmental Cognitive Neuroscience, 1(4), 364-376.

González, M. R., Gasco, J., and Llopis, J. (2016). Facebook and academic performance: A positive outcome. Journal of Cybertherapy and Rehabilitation, 1, 2.7.

Griffiths, M. D., Lopez-Fernandez, O., Throuvala, M., Pontes, H., \& Kuss, D. J. (2018). Excessive and problematic use of social media in adolescence: A brief overview. Report submitted to the UK Parliament Science and Technology Committee (Impact of social media and screen-use on young people's health inquiry). Nottingham: Nottingham Trent University. Located

at: http://data.parliament.uk/writtenevidence/committeeevidence.svc/evidencedocument/science-andtechnology-committee/social-media-and-mental-health/written/81105.pdf

Griffiths, M. D., and Kuss, D. J. (2017). Adolescent social media addiction (revisited). Education and Health, 35(3), 49-52.

Griffiths, M. D., Kuss, D. J. \& Demetrovics, Z. (2014). Social networking addiction: An overview of preliminary findings. In K. Rosenberg \& L. Feder (Eds.), Behavioral Addictions: Criteria, Evidence and Treatment (pp. 119-141). New York: Elsevier.

Guo, Y., You, X., Gu, Y., Wu, G., and Xu, C. (2018). A moderated mediation model of the relationship between quality of social relationships and internet addiction: mediation by loneliness and moderation by dispositional optimism. Current Psychology, 1-11.

Hahn, L. S. (2013). Television consumption and empathy: A connection? Kent State University.

Hair, J. F., and Hult, G. T. M. (2016). A primer on partial least squares structural equation modeling (PLSSEM): Sage Publications.

Hair, J. F., Ringle, C. M., and Sarstedt, M. (2011). PLS-SEM: Indeed a silver bullet. The Journal of Marketing Theory and Practice, 19(2), 139-152.

Hatfield, E., Cacioppo, J., and Rapson, R. (1994). Emotional contagion: Cambridge studies in emotion and social interaction. Cambridge, UK: Cambridge University Press. errors-in-variables regression model when the variances of the measurement errors vary between the observations. Statistics in Medicine, 21, 10891101.

Hawi, N., and Samaha, M. (2019). Identifying commonalities and differences in personality characteristics of Internet and social media addiction profiles: traits, self-esteem, and self-construal. Behaviour \& Information Technology, 38(2), 110-119.

Henseler, J., Ringle Christian, M., and Sinkovics Rudolf, R. (2009). The use of partial least squares path modeling in international marketing. In R. S. Rudolf and N. G. Pervez (Eds.), New Challenges to International Marketing (Vol. 20, pp. 277-319): Emerald Group Publishing Limited. 
Henseler, J., Ringle, C. M., and Sarstedt, M. (2015). A new criterion for assessing discriminant validity in variance-based structural equation modeling. Journal of the Academy of Marketing Science, 43(1), 115135.

Hétu, S., Taschereau-Dumouchel, V., and Jackson, P. L. (2012). Stimulating the brain to study social interactions and empathy. Brain Stimulation, 5(2), 95-102.

Hew, T.-S., and Syed A. Kadir, S. L. (2017). Applying Channel Expansion and Self-Determination Theory in predicting use behaviour of cloud-based VLE. Behaviour \& Information Technology, 1-22.

Hirn, S. L., Thomas, J., and Zoelch, C. (2019). The role of empathy in the development of social competence: a study of German school leavers. International Journal of Adolescence and Youth, 24(4), 395-407.

Hodges, S. D., Kiel, K. J., Kramer, A. D., Veach, D., and Villanueva, B. R. (2010). Giving birth to empathy: The effects of similar experience on empathic accuracy, empathic concern, and perceived empathy. Personality and Social Psychology Bulletin, 36(3), 398-409.

Horzum, M. B. (2016). Examining the relationship to gender and personality on the purpose of Facebook usage of Turkish university students. Computers in Human Behavior, 64, 319-328.

Hou, Y., Xiong, D., Jiang, T., Song, L., and Wang, Q. (2019). Social media addiction: Its impact, mediation, and intervention. Cyberpsychology: Journal of Psychosocial Research on Cyberspace, 13(1).

Hui, B. P. H., AM, S. W., and Pun, N. (2019). Disentangling the effects of empathy components on Internet gaming disorder: A study of vulnerable youth in China. Journal of Behavioral Addictions, 8(1), 181-189.

Ibrahim, T. (2019). The pattern of relationship between attachment styles, gaming addiction and empathetic tendency among adolescents. Eurasian Journal of Educational Research, 19(83), 125-144.

Jackson, P. L., Eugène, F., and Tremblay, M.-P. B. (2015). Improving empathy in the care of pain patients. AJOB Neuroscience, 6(3), 25-33.

Jeon, H. J., Kim, S., Chon, W.-H., and Ha, J. H. (2018). Is Internet overuse associated with impaired empathic ability in Korean college students? Medicine, 97(39).

Jeong, H., and Lee, Y. (2015). Smartphone addiction and empathy among nursing students. Advanced Science and Technology Letters, 88, 224-228.

Jiao, C., Wang, T., Peng, X., and Cui, F. (2017). Impaired empathy processing in individuals with internet addiction disorder: An event-related potential study. Frontiers in Human Neuroscience, 11(498).

JING, J., GAO, C., and NIU, G. (2017). The effect of internet use on empathy. Advances in Psychological Science, 25(4), 652-661.

Jordan, C. J., and Andersen, S. L. (2017). Sensitive periods of substance abuse: Early risk for the transition to dependence. Developmental Cognitive Neuroscience, 25, 29-44. 
Jütten, L. H., Mark, R. E., and Sitskoorn, M. M. (2019). Empathy in informal dementia caregivers and its relationship with depression, anxiety, and burden. International Journal of Clinical and Health Psychology, 19(1), 12-21.

Kandell, J. J. (1998). Internet addiction on campus: The vulnerability of college students. Cyberpsychology \& Behavior, 1(1), 11-17.

Kaukiainen, A., Björkqvist, K., Lagerspetz, K., Österman, K., Salmivalli, C., Rothberg, S., et al. (1999). The relationships between social intelligence, empathy, and three types of aggression. Aggressive Behavior, 25(2), 81-89.

Kim, J. W., and Chock, T. M. (2017). Personality traits and psychological motivations predicting selfie posting behaviors on social networking sites. Telematics and Informatics, 34(5), 560-571.

Kircaburun, K. (2016). Effects of gender and personality differences on Twitter addiction among Turkish undergraduates. Journal of Education and Practice, 7(24), 33-42.

Kircaburun, K., Alhabash, S., Tosuntaş, Ş. B., and Griffiths, M. D. (2018). Uses and gratifications of problematic social media use among university students: A simultaneous examination of the Big Five personality traits, social media platforms, and social media use motives. International Journal of Mental Health and Addiction, 1-23.

Kircaburun, K., and Griffiths, M. D. (2018). Instagram addiction and the Big Five of personality: The mediating role of self-liking. Journal of Behavioral Addictions, 7(1), 158-170.

Kizgin, H., Jamal, A., Dey, B. L., and Rana, N. P. (2018). The impact of social media on consumers' acculturation and purchase intentions. Information Systems Frontiers, 20(3), 503-514.

Kosinski, M., Bachrach, Y., Kohli, P., Stillwell, D., and Graepel, T. (2014). Manifestations of user personality in website choice and behaviour on online social networks. Machine Learning, 95(3), 357380.

Krahé, B., and Möller, I. (2010). Longitudinal effects of media violence on aggression and empathy among German adolescents. Journal of Applied Developmental Psychology, 31(5), 401-409.

Kumar, B., and Banik, P. (2019). Social network, Facebook use and loneliness: A comparative analysis between public and private university students in Bangladesh. International Journal of Psychological and Brain Sciences, 4(2), 20.

Kuss, D. J., D Griffiths, M. D., Karila, L., and Billieux, J. (2014). Internet addiction: A systematic review of epidemiological research for the last decade. Current Pharmaceutical Design, 20(25), 4026-4052.

Kuss, D. J., and Griffiths, M. D. (2017). Social networking sites and addiction: Ten lessons learned. International Journal of Environmental Research and Public Health, 14(3), 311.

Kuss, D. J., and Griffiths, M. D. (2011). Online social networking and addiction-A review of the psychological literature. International Journal of Environmental Research and Public Health, 8(9), 35283552. 
Lachmann, B., Sindermann, C., Sariyska, R. Y., Luo, R., Melchers, M. C., Becker, B., et al. (2018). The role of empathy and life satisfaction in Internet and Smartphone Use Disorder. Frontiers in Psychology, 9(398).

Liau, A. K., Choo, H., Li, D., Gentile, D. A., Sim, T., and Khoo, A. (2015). Pathological video-gaming among youth: a prospective study examining dynamic protective factors. Addiction Research Theory, 23(4), 301308.

Liau, A. K., Tan, T. K., Li, D., and Khoo, A. (2012). Factorial invariance of the Personal Strengths Inventory2 for children and adolescents across school level and gender. European Journal of Psychology of Education, 27(4), 451-465.

Linz, D. G., Donnerstein, E., and Penrod, S. (1988). Effects of long-term exposure to violent and sexually degrading depictions of women. Journal of Personality and Social Psychology, 55(5), 758.

Liu, B., and Wei, L. (2018). Modeling social support on social media: Effect of publicness and the underlying mechanisms. Computers in Human Behavior, 87, 263-275.

Loudin, J. L., Loukas, A., and Robinson, S. (2003). Relational aggression in college students: Examining the roles of social anxiety and empathy. Aggressive Behavior: Official Journal of the International Society for Research on Aggression, 29(5), 430-439.

Marengo, D., Poletti, I., and Settanni, M. (2020). The interplay between neuroticism, extraversion, and social media addiction in young adult Facebook users: Testing the mediating role of online activity using objective data. Addictive Behaviors, 102, 106150.

Maslow, A. H. (1943). A theory of human motivation. Psychological Review, 50(4), 370.

McClelland, D. C. (1965). Toward a theory of motive acquisition. American Psychologist, 20(5), 321.

Mcllwain, D. (2003). Bypassing empathy: A Machiavellian theory of mind and sneaky power. In B. Repacholi and V. laughter (Eds.), Individual differences in theory of mind: Implications for typical and atypical development. (pp. 39-66). New York: Psychology Press.

Mehrabian, A., and Epstein, N. (1972). A measure of emotional empathy. Journal of Personality, 40(4), 525-543.

Melchers, M., Li, M., Chen, Y., Zhang, W., and Montag, C. (2015). Low empathy is associated with problematic use of the Internet: Empirical evidence from China and Germany. Asian Journal of Psychiatry, 17, 56-60.

Melchers, M. C., Li, M., Haas, B. W., Reuter, M., Bischoff, L., and Montag, C. (2016). Similar personality patterns are associated with empathy in four different countries. Frontiers in Psychology, 7(290).

Miller, P. A., and Eisenberg, N. (1988). The relation of empathy to aggressive and externalizing/antisocial behavior. Psychological Bulletin, 103(3), 324.

Misoch, S. (2015). Stranger on the internet: Online self-disclosure and the role of visual anonymity. Computers in Human Behavior, 48, 535-541. 
Moore, K., and McElroy, J. C. (2012). The influence of personality on Facebook usage, wall postings, and regret. Computers in Human Behavior, 28(1), 267-274.

Morelli, S. A., Lieberman, M. D., and Zaki, J. (2015). The emerging study of positive empathy. Social and Personality Psychology Compass, 9(2), 57-68.

Nettle, D. (2007). Empathizing and systemizing: What are they, and what do they contribute to our understanding of psychological sex differences? British Journal of Psychology, 98(2), 237-255.

Nie, N.H., Hillygus, D.S. and Erbring, L. (2008). Internet Use, Interpersonal Relations, and Sociability: A Time Diary Study. In The Internet in Everyday Life (eds B. Wellman and C. Haythornthwaite). doi:10.1002/9780470774298.ch7Penner, L. A. (2002). Dispositional and organizational influences on sustained volunteerism: An interactionist perspective. Journal of Social Issues, 58(3), 447-467.

Ponnampalam, M. (2018). F246. A systematic review comparing the neural correlates of empathy associated with the onset and progression of Schizophrenia. Schizophrenia Bulletin, 44(Suppl 1), S318.

Przybylski, A., and Murayama, K. (2013). Motivational, emotional, and behavioral correlates of fear of missing out. Computers in Human Behavior, 29 (4), 1841-1848.

Rajesh, T., and Rangaiah, B. (2020). Facebook addiction and personality. Heliyon, 6(1), e03184.

Rathore, A. (2019). A critical review on effect of social networking sites on academic acheivement among introverts and extroverts. SJSS), 1(4).

Riess, H. (2015). The impact of clinical empathy on patients and clinicians: Understanding empathy's side effects. AJOB Neuroscience, 6(3), 51-53.

Rifkin, J. (2009). The empathic civilization: The race to global consciousness in a world in crisis: Penguin.

Rubin, A. M. (1993). Audience activity and media use. Communications Monographs, 60(1), 98-105.

Ryan, T., Chester, A., Reece, J., \& Xenos, S. (2014). The uses and abuses of Facebook: A review of Facebook addiction. Journal of Behavioral Addictions, 3(3), 133-148.

https://doi.org/10.1556/JBA.3.2014.016 Ryan, T., and Xenos, S. (2011). Who uses Facebook? An investigation into the relationship between the Big Five, shyness, narcissism, loneliness, and Facebook usage. Computers in Human Behavior, 27(5), 1658-1664.

Salehan, M., and Negahban, A. (2013). Social networking on smartphones: When mobile phones become addictive. Computers in Human Behavior, 29(6), 2632-2639.

Sawyer, R. K. (2011). Explaining creativity: The science of human innovation. Oxford University Press.

Schutte, N. S., Malouff, J. M., Hall, L. E., Haggerty, D. J., Cooper, J. T., Golden, C. J., et al. (1998). Development and validation of a measure of emotional intelligence. Personality and Individual Differences, 25(2), 167-177.

Shalchi, B. (2018). Big five model in explanation of associations between personality and clinical empathy among nurses. Razi Journal of Medical Sciences, 25(169).

Shamay-Tsoory, S. G. (2011). The neural bases for empathy. The Neuroscientist, 17(1), 18-24. 
Sherlock, M., \& Wagstaff, D. L. (2019). Exploring the relationship between frequency of Instagram use, exposure to idealized images, and psychological well-being in women. Psychology of Popular Media Culture, 8(4), 482-490. https://doi.org/10.1037/ppm0000182 Singer, T., Seymour, B., O'doherty, J., Kaube, H., Dolan, R. J., and Frith, C. D. (2004). Empathy for pain involves the affective but not sensory components of pain. Science, 303(5661), 1157-1162.

Sirola, A., Kaakinen, M., Savolainen, I., and Oksanen, A. (2019). Loneliness and online gamblingcommunity participation of young social media users. Computers in Human Behavior, 95, 136-145.

Sorokowska, A., Oleszkiewicz, A., Frackowiak, T., Pisanski, K., Chmiel, A., and Sorokowski, P. (2016). Selfies and personality: Who posts self-portrait photographs? Personality and Individual Differences, 90, 119-123.

Taher, M., Abolghasemi, A., Hajloo, N., and Narimani, M. (2016). The comparison of efficacy of empathy and anger management trainings on social cognition and symptoms of students with oppositional defiant disorder. Quarterly Journal of Child Mental Health, 2(4), 59-74.

Tang, J.-H., Chen, M.-C., Yang, C.-Y., Chung, T.-Y., and Lee, Y.-A. (2016). Personality traits, interpersonal relationships, online social support, and Facebook addiction. Telematics and Informatics, 33(1), 102-108.

Throuvala, M. A., Griffiths, M. D., Rennoldson, M., and Kuss, D. J. (2019). School-based prevention for adolescent Internet addiction: Prevention is the key. A systematic literature review. Current Neuropharmacology, 17(6), 507-525.

Tsai, H. F., Cheng, S. H., Yeh, T. L., Shih, C.-C., Chen, K. C., Yang, Y. C., et al. (2009). The risk factors of Internet addiction-A survey of university freshmen. Psychiatry Research, 167(3), 294-299.

Tunc-Aksan, A., and Akbay, S. E. (2019). Smartphone Addiction, Fear of Missing Out, and Perceived Competence as Predictors of Social Media Addiction of Adolescents. European Journal of Educational Research, 8(2), 559-566.

van den Eijnden, R. J., Lemmens, J. S., and Valkenburg, P. M. (2016). The social media disorder scale. Computers in Human Behavior, 61, 478-487.

Wakabayashi, A., and Kawashima, H. (2015). Is empathizing in the E-S theory similar to agreeableness? The relationship between the EQ and SQ and major personality domains. Personality and Individual Differences, 76, 88-93.

Wang, C.-W., Ho, R. T., Chan, C. L., and Tse, S. (2015a). Exploring personality characteristics of Chinese adolescents with internet-related addictive behaviors: Trait differences for gaming addiction and social networking addiction. Addictive Behaviors, 42, 32-35.

Wang, C.-W., Ho, R. T. H., Chan, C. L. W., and Tse, S. (2015b). Exploring personality characteristics of Chinese adolescents with internet-related addictive behaviors: Trait differences for gaming addiction and social networking addiction. Addictive Behaviors, 42, 32-35.

Wang, T., Ge, Y., Zhang, J., Liu, J., and Luo, W. (2014). The capacity for pain empathy among urban Internet-addicted left-behind children in China: An event-related potential study. Computers in Human Behavior, 33, 56-62. 
Wegmann, E., and Brand, M. (2016). Internet-communication disorder: It's a matter of social aspects, coping, and Internet-use expectancies. Frontiers in Psychology, 7, 1747.

Wei, L., and Liu, B. (2020). Reactions to others' misfortune on social media: Effects of homophily and publicness on schadenfreude, empathy, and perceived deservingness. Computers in Human Behavior, 102, 1-13.

Wichstrom, L., Stenseng, F., Belsky, J., von Soest, T., and Hygen, B. W. (2019). Symptoms of Internet Gaming Disorder in Youth: Predictors and Comorbidity. Journal of Abnormal Child Psychology, 47(1), 7183.

Wölfer, R., Cortina, K. S., and Baumert, J. (2012). Embeddedness and empathy: How the social network shapes adolescents' social understanding. Journal of Adolescence, 35(5), 1295-1305.

Wolniewicz, C. A., Tiamiyu, M. F., Weeks, J. W., and Elhai, J. D. (2018). Problematic smartphone use and relations with negative affect, fear of missing out, and fear of negative and positive evaluation.

Psychiatry Research, 262, 618-623.

Young, K. S. (1998). Caught in the net: How to recognize the signs of internet addiction--and a winning strategy for recovery. John Wiley \& Sons.

Yujia, R., Jiao, Y., and Liqiong, L. (2017). Social anxiety and internet addiction among rural left-behind children: the mediating effect of loneliness. Iranian Journal of Public Health, 46(12), 1659.

Zhao, F., Zhang, Z.-H., Bi, L., Wu, X.-S., Wang, W.-J., Li, Y.-F., et al. (2017). The association between life events and internet addiction among Chinese vocational school students: The mediating role of depression. Computers in Human Behavior, 70, 30-38.

Zhou, Y., Li, D., Li, X., Wang, Y., and Zhao, L. (2017). Big five personality and adolescent Internet addiction: The mediating role of coping style. Addictive Behaviors, 64, 42-48. 